\title{
Tumor Necrosis Factor- $a$ Gene Expression in Epicardial Adipose Tissue is Related to Coronary Atherosclerosis Assessed by Computed Tomography
}

\author{
Toshiro Kitagawa ${ }^{1}$, Hideya Yamamoto ${ }^{1}$, Takuya Hattori², Kazuhiro Sentani², Shinya Takahashi ${ }^{3}$, \\ Atsuhiro Senoo ${ }^{1}$, Yumiko Kubo ${ }^{1}$, Wataru Yasui ${ }^{2}$, Taijiro Sueda ${ }^{3}$ and Yasuki Kihara ${ }^{1}$ \\ ${ }^{1}$ Department of Cardiovascular Medicine, Hiroshima University Graduate School of Biomedical and Health Sciences, Hiroshima, Japan \\ ${ }^{2}$ Department of Molecular Pathology, Hiroshima University Institute of Biomedical and Health Sciences, Hiroshima, Japan \\ ${ }^{3}$ Department of Cardiovascular Surgery, Hiroshima University Hospital, Hiroshima, Japan
}

\begin{abstract}
Aims: Tumor necrosis factor (TNF)- $\alpha$ reportedly has key pro-inflammatory properties in both atherosclerosis and adipocytes. To further investigate the biologic impact of epicardial adipose tissue (EAT) on coronary atherosclerosis, we evaluated the relationship between TNF- $\alpha$ gene expression in EAT and clinically-assessed coronary atherosclerosis on computed tomography (CT).

Methods: We studied 47 patients before cardiac surgery (coronary artery bypass grafting [CABG], $n=26$; non-CABG, $n=21$ ), assessing visceral adipose tissue (VAT) area, EAT volume, coronary calcium score (CCS), and the presence of non- and/or partially-calcified coronary plaque (NCP) on CT angiography. EAT and subcutaneous adipose tissue (SAT) samples were obtained during cardiac surgery. TNF- $\alpha$ mRNA in EAT was measured using quantitative real-time PCR, and normalized to that of SAT as control adipose tissue.

Results: There was no difference in the TNF- $\alpha$ expression level between patients scheduled for CABG and non-CABG surgery $(p=0.23)$, or among the subgroups based on CCS $(p=0.68)$, while patients with NCP had the higher TNF- $\alpha$ expression level than those without NCP (median [interquartile range], $2.50[1.01-5.53]$ versus. $1.03[0.64-2.16], p=0.022)$. On multivariate analysis adjusted for age, sex, coronary risk factors, statin therapy, CABG versus non-CABG, VAT area, and EAT volume, the presence of NCP had close correlation with the elevated TNF- $\alpha$ expression level $(\beta=0.79$, $p=0.003$ ).

Conclusions: TNF- $\alpha$ expressed regionally in EAT may exert potent effects on the progression of coronary atherosclerosis, suggesting a contribution of EAT to coronary artery disease through behavior of molecule.
\end{abstract}

Key words: Epicardial adipose tissue, Tumor necrosis factor- $\alpha$, Coronary atherosclerosis, Computed tomography

\section{Introduction}

There has been a great deal of recent interest in the clinical and pathologic significance of epicardial adipose tissue (EAT) in coronary artery disease (CAD).

Address for correspondence: Toshiro Kitagawa, Department of Cardiovascular Medicine, Hiroshima University Graduate School of Biomedical \& Health Sciences, 1-2-3 Kasumi, Minami-Ku, Hiroshima 734-8551, Japan

E-mail: toshirok@hiroshima-u.ac.jp

Received: May 8, 2017

Accepted for publication: July 26, 2017
As EAT surrounds coronary arteries, it is thought that it acts directly on coronary artery walls and contributes to the initiation and progression of coronary atherosclerosis ${ }^{1)}$. There have been reports suggesting that higher EAT volume is associated with coronary calcification, coronary stenosis, coronary plaque morphology, and the development of new non-calcified coronary plaque on cardiac computed tomography $(\mathrm{CT})^{2-7)}$. On the other hand, a recent study in a diverse population of symptomatic patients did not find a significant relationship between EAT volume and the presence or extent of coronary calcification measured by cardiac 
$\mathrm{CT}^{8)}$. Thus, while higher EAT volume appears to have an influence on coronary atherosclerosis, EAT requires elucidation of its other features, such as its biologic characteristics, to improve our understanding of the pathophysiologic mechanisms active in EAT that contribute to the pathogenesis of CAD.

As EAT is reported to be a source of inflammatory cytokines and mediators ${ }^{9-11)}$, it can be thought of as an important endocrine organ lying adjacent to the coronary arteries. We have recently reported that macrophage infiltration and neoangiogenesis in EAT verified by immunohistochemical staining correlate with moderate coronary calcification and non-calcified coronary plaque component on CT images, suggestive of the progressive stage of coronary atherosclerosis ${ }^{12}$. While our findings suggest a biologic role for EAT in the progression of coronary atherosclerosis, the mechanism by which it does so remains unclear.

Tumor necrosis factor (TNF)- $\alpha$ is one of major monocyte-derived cytokines and exerts potent proinflammatory effects on atherosclerosis ${ }^{13)}$. TNF- $\alpha$ also functions as a determinant of cytokine dysregulation in adipocytes ${ }^{14)}$. Suganami et al. have reported that TNF- $\alpha$ derived from adipocytes and macrophages plays a major role in the co-culture-induced inflammatory changes ${ }^{15)}$. These suggest that TNF- $\alpha$ is an important mediator of inflammation in adipose tissue. Thus, TNF- $\alpha$ expressed in EAT needs to be investigated in relation to clinically-assessed coronary atherosclerosis.

\section{Aim}

We examined the gene expression level of TNF- $\alpha$ in EAT, and sought to evaluate the relationship between EAT TNF- $\alpha$ expression and the appearance and severity of coronary atherosclerosis based on cardiac CT images.

\section{Methods}

\section{Study Patients}

We enrolled 47 patients referred for cardiac CT for the investigation and diagnosis of CAD in preparation for elective coronary artery bypass graft surgery (CABG, $n=26$ ) or cardiac valve surgery (non-CABG, $n=21$ [aortic valve repair, $n=12$; mitral valve repair, $n=9)$. Patients who had previously undergone percutaneous coronary intervention, and/or CABG, and those receiving dialysis, were not enrolled, as these would have been potentially confounding factors in the analysis of coronary calcification and plaques on CT images. Clinical information, including coronary risk factors and statin therapy (duration $>6$ months), was recorded. Serum lipid levels, hemoglobin A1c, and C-reactive protein (CRP) concentration measured just before surgery were also recorded.

In each patient, specimens of EAT adjacent to the left anterior descending (left EAT) and right coronary arteries (right EAT) were obtained during cardiac surgery (two EAT samples per patient). Additionally, subcutaneous adipose tissue (one sample per patient) was taken from the subcutaneous fat on the sternum in each patient as control adipose tissue ${ }^{12)}$. The size of each specimen was generalized ( $5 \mathrm{~mm}$ in longest diameter). These samples were subjected to further analyses with immunohistochemical staining and quantitative realtime polymerase chain reaction (qPCR) for TNF- $\alpha$ gene expression.

Our study complied with the Declaration of Helsinki. Our hospital's ethics committee approved the study protocol, and written informed consent was obtained from all patients. The protocol has been published in the Japan UMIN Clinical Trials Registry (ID: UMIN000010654).

\section{Cardiac CT Protocol}

All patients underwent cardiac CT imaging using a 320-slice CT scanner (Aquilion One; Toshiba Medical Systems, Tokyo, Japan) within 1 month prior to cardiac surgery, as in our previous studies ${ }^{12,16)}$. A plain scan was undertaken to measure coronary calcium score (CCS) according to the standard Agatston method (slice thickness $3.0 \mathrm{~mm}$; maximum tube current 270 $\mathrm{mA}$; tube voltage $120 \mathrm{kV}$ ). The data set for coronary CT angiography (CCTA) was then acquired using the HeartNAVI ${ }^{\circledR}$ system (collimation $320 \times 0.5 \mathrm{~mm}$; tube current 350-580 mA; tube voltage $120 \mathrm{kV}$; Toshiba Medical Systems) under retrospective electrocardiography gating. The effective radiation dose for CCTA estimated on the basis of the dose-length product was $8 \pm 4 \mathrm{mSv}$ per patient ${ }^{12)}$. All reconstructed CT image data were transferred to an offline workstation (Advantage Workstation Ver. 4.2, GE Healthcare, Waukesha, WI, USA) for post-processing and image analysis.

\section{Analyses of Adipose Tissues and Coronary Athero- sclerosis on CT}

Two blinded independent observers undertook all CT image analyses.

The quantification of adipose tissues was performed on plain CT images using dedicated software (Virtual Place, AZE Inc., Tokyo, Japan), as previously reported $^{4,12,17,18)}$. Intra-abdominal visceral adipose tissue (VAT) area, defined as the intraperitoneal adipose tissue area with a CT density ranging from -150 to -50 Hounsfield units (HU), was calculated at the level of the umbilicus. Then, EAT volume was measured by calculating the total sum of EAT areas from 1 
Table 1. Clinical characteristics of the entire study cohort, and after allocation to the subgroups based on cardiac surgery procedure, CCS, and the presence or absence of NCP on CCTA.

\begin{tabular}{|c|c|c|c|c|c|c|c|c|c|c|c|}
\hline Characteristics & $\begin{array}{l}\text { Total } \\
(n=47)\end{array}$ & $\begin{array}{l}\text { CABG } \\
(n=26)\end{array}$ & $\begin{array}{l}\text { Non- } \\
\text { CABG } \\
(n=21)\end{array}$ & $p$ value & $\begin{array}{l}\text { CCS } \\
\text { mild } \\
(n=11)\end{array}$ & $\begin{array}{l}\text { CCS } \\
\text { moderate } \\
(n=15)\end{array}$ & $\begin{array}{l}\text { CCS } \\
\text { severe } \\
(n=21)\end{array}$ & $p$ value & $\begin{array}{l}\text { NCP } \\
\text { presence } \\
(n=23)\end{array}$ & $\begin{array}{l}\mathrm{NCP} \\
\text { absence } \\
(n=24)\end{array}$ & $p$ value \\
\hline Age (years) & $71 \pm 9$ & $69 \pm 7$ & $72 \pm 10$ & 0.29 & $66 \pm 12$ & $72 \pm 9$ & $72 \pm 6$ & 0.16 & $69 \pm 8$ & $72 \pm 10$ & 0.32 \\
\hline Male sex & $23(49)$ & $16(62)$ & $7(33)$ & 0.055 & $4(36)$ & $6(40)$ & $13(62)$ & 0.27 & $15(65)$ & $8(33)$ & 0.029 \\
\hline BMI $\left(\mathrm{kg} / \mathrm{m}^{2}\right)$ & $23 \pm 3$ & $23 \pm 3$ & $23 \pm 3$ & 0.96 & $24 \pm 3$ & $23 \pm 3$ & $23 \pm 4$ & 0.47 & $24 \pm 3$ & $23 \pm 3$ & 0.15 \\
\hline Hypertension & $32(68)$ & $18(69)$ & $14(67)$ & 0.85 & $8(72)$ & $8(53)$ & $16(76)$ & 0.33 & $16(70)$ & $16(67)$ & 0.83 \\
\hline Hyperlipidemia & $27(57)$ & $17(65)$ & $10(48)$ & 0.22 & $6(55)$ & $7(47)$ & $14(67)$ & 0.48 & $15(65)$ & $12(50)$ & 0.29 \\
\hline Diabetes mellitus & $17(36)$ & $13(50)$ & $4(19)$ & 0.028 & $2(18)$ & $3(20)$ & $12(57)$ & 0.027 & $12(52)$ & $5(21)$ & 0.025 \\
\hline Current smoking & $13(28)$ & $11(42)$ & $2(10)$ & 0.013 & $3(27)$ & $3(20)$ & $7(33)$ & 0.68 & $11(48)$ & $2(8)$ & 0.003 \\
\hline Statin use & $21(45)$ & $15(58)$ & $6(29)$ & 0.046 & $4(36)$ & $6(40)$ & $11(52)$ & 0.62 & $12(52)$ & $9(38)$ & 0.31 \\
\hline \multicolumn{12}{|l|}{ Blood examination } \\
\hline $\operatorname{HDL}(\mathrm{mg} / \mathrm{dl})$ & $52 \pm 14$ & $51 \pm 13$ & $54 \pm 15$ & 0.44 & $58 \pm 15$ & $49 \pm 13$ & $52 \pm 13$ & 0.24 & $49 \pm 13$ & $55 \pm 15$ & 0.13 \\
\hline $\mathrm{LDL}(\mathrm{mg} / \mathrm{dl})$ & $111 \pm 28$ & $110 \pm 27$ & $112 \pm 30$ & 0.88 & $115 \pm 23$ & $111 \pm 34$ & $109 \pm 27$ & 0.76 & $109 \pm 28$ & $113 \pm 29$ & 0.74 \\
\hline Triglyceride $(\mathrm{mg} / \mathrm{dl})$ & $125 \pm 63$ & $141 \pm 76$ & $104 \pm 33$ & 0.17 & $136 \pm 72$ & $101 \pm 42$ & $136 \pm 69$ & 0.16 & $149 \pm 78$ & $101 \pm 32$ & 0.047 \\
\hline Hemoglobin A1c (\%) & $6.2 \pm 0.8$ & $6.5 \pm 1.0$ & $5.9 \pm 0.5$ & 0.018 & $5.9 \pm 0.5$ & $5.9 \pm 0.5$ & $6.6 \pm 1.0$ & 0.006 & $6.5 \pm 1.0$ & $6.0 \pm 0.6$ & 0.052 \\
\hline $\mathrm{CRP}(\mathrm{mg} / \mathrm{L})$ & $2.1 \pm 3.9$ & $2.9 \pm 5.1$ & $1.0 \pm 0.8$ & 0.46 & $0.7 \pm 0.5$ & $1.7 \pm 1.7$ & $3.0 \pm 5.5$ & 0.24 & $3.1 \pm 5.3$ & $1.1 \pm 0.8$ & 0.39 \\
\hline EAT volume (ml) & $117 \pm 52$ & $122 \pm 58$ & $110 \pm 45$ & 0.84 & $111 \pm 50$ & $115 \pm 46$ & $126 \pm 57$ & 0.60 & $130 \pm 56$ & $104 \pm 45$ & 0.25 \\
\hline
\end{tabular}

Values are expressed as mean \pm standard deviation or number (percent).

BMI, body mass index; CABG, coronary artery bypass graft surgery; CCS, coronary calcium score; CCTA, coronary computed tomography angiography; CRP, C-reactive protein; EAT, epicardial adipose tissue; HDL, high-density lipoprotein; LDL, low-density lipoprotein; NCP, non-calcified coronary plaque.

$\mathrm{cm}$ above the left main coronary artery to the left ventricular apex on images taken at $1 \mathrm{~cm}$ intervals: EAT was defined as adipose tissue surrounding the myocardium and limited by the epicardium. The EAT area of the epicardium was manually traced and defined as the area with a density range between -250 and -30 HU. Although differing in the density range between VAT and EAT, the above methods are traditionally used to measure adipose tissue amounts clinically ${ }^{4,12,17-19)}$.

In all coronary segments $>2 \mathrm{~mm}$ in diameter on CCTA, the presence or absence of non-calcified coronary plaque (NCP) was evaluated as in our previous studies ${ }^{4,20-22)}$. The definition of NCP was done as a low-density mass $>1 \mathrm{~mm}^{2}$ in size, located within the vessel wall and clearly distinguishable from the contrast-enhanced coronary lumen and the surrounding pericardial tissue. When partially-calcified coronary plaques containing both NCP and coronary calcium deposits (a structure on the vessel wall with a CT density above that of the contrast-enhanced coronary lumen or with a CT density of $>130 \mathrm{HU}$ ) were observed, the patient was determined to have NCP. In each segment with NCP, the proportion of lumen stenosis was determined by measuring the luminal diameter at the narrowest site and comparing it with the diameter of the normal proximal site: $>50 \%$ stenosis was considered to represent clinical obstruction.
If the initial assessment of the presence or absence of NCP and coronary stenosis differed between the two independent observers, an agreement was reached by consensus.

\section{Immunohistochemical Staining and qPCR}

The protocol for the immunohistochemical staining of the adipose tissue samples (left and right EATs in each patient) was explained in our previous report ${ }^{12)}$. We quantified the infiltration of macrophages into adipose tissue using a primary antibody against CD68 (1:100, clone KP-1; Dako, Glostrup, Denmark). CD68positive individual cells were counted in three random high-power fields (one field corresponded to a circle of radius $250 \mu \mathrm{m}$ ) in each left and right EAT specimen, and the summed number of cells was reported for each patient.

Total RNA was isolated from the frozen adipose tissue samples (left EAT, right EAT, and SAT in each patient) using TRIzol reagent (Invitrogen, Carlsbad, CA, USA) and $1 \mu \mathrm{g}$ of total RNA was converted to complementary DNA (cDNA) using High-Capacity cDNA Reverse Transcription Kit (Applied Biosystems, Foster City, CA, USA). PCR reactions were performed with SYBR Select Master Mix (Applied Biosystems). Real-time detection of the emission intensity of SYBR green bound to double-stranded DNA was performed 


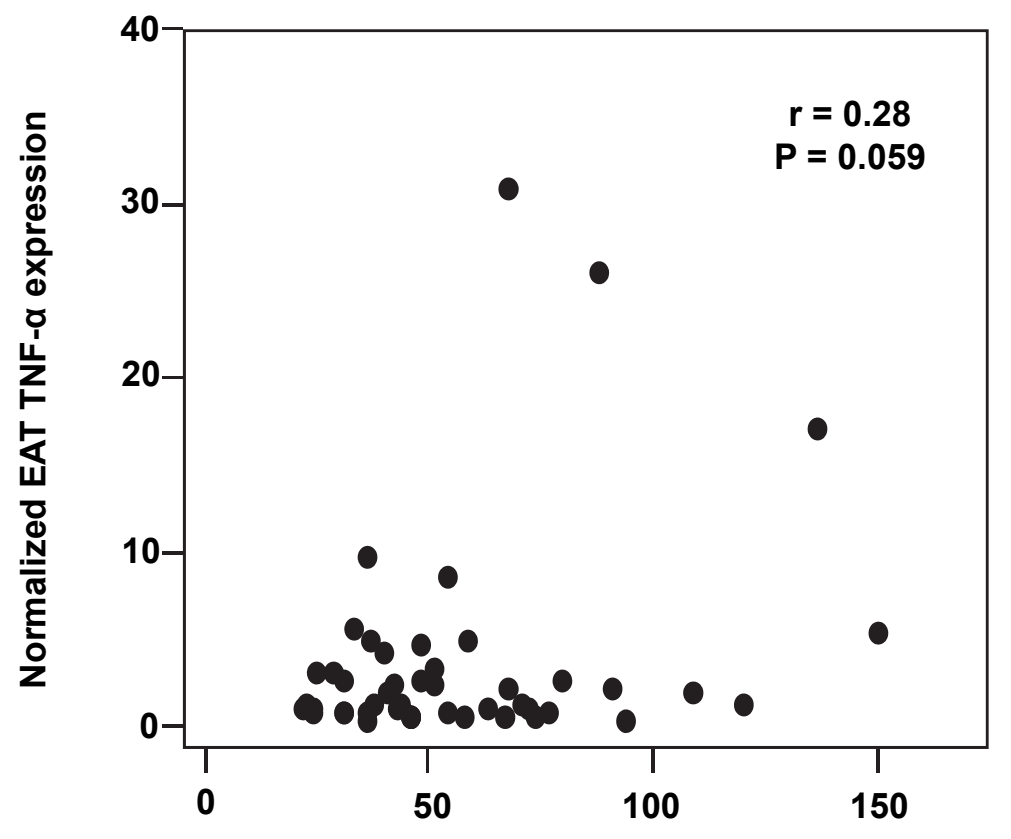

EAT CD68+ macrophage counts /patient

Fig. 1. There was no significant correlation between $\mathrm{CD} 68^{+}$macrophage infiltration and normalized tumor necrosis factor (TNF)- $\alpha$ expression in epicardial adipose tissue (EAT).

with a CFX Connect Real-Time System (Bio-Rad Laboratories, Hercules, CA, USA). The following primers were used: 5'-GACAAGCCTGTAGCCCATGTTGTA-3' and 5'-CAGCCTTGGCCCTTGAAGA-3' for TNF- $\alpha$, and 5'-GCCCTGAGGCACTCTTCCA-3' and $5^{\prime}$-GCGGATGTCCACGTCACA-3' for $\beta$-actin. $\beta$-Actin-specific PCR products, which were amplified from the same RNA samples, served as internal controls. Data were analyzed with the $\Delta \Delta \mathrm{CT}$ method, and relative expression was normalized to that of $\beta$-actin. Three assays were performed for each sample, and the mean of the three assays was used as the relative quantification value.

We previously confirmed that the histologic evidence of macrophage infiltration was much more extensive in EAT than in paired SAT samples, implying that EAT is an inflammatory adipose tissue ${ }^{12)}$. To assess the EAT-specific condition, TNF- $\alpha$ mRNA expression in EAT was normalized to that of paired SAT specimen as control adipose tissue, and the mean of the left and right normalized mRNA expression levels was reported for each patient.

\section{Subgroup Allocation and Statistical Analysis}

Patients were divided into one of three groups based on CCS in reference to previous studies: mild, $0-100$; moderate, $101-400$; severe, $>400^{23-25)}$. They were also divided into one of two groups on the basis of presence or absence of NCP on CCTA.

Macrophage count and normalized mRNA expression level are expressed as the median and interquartile range, and other continuous variables are expressed as the mean \pm standard deviation. The Wilcoxon signedrank test was used to compare paired parameters. Student's $t$ test or the Mann-Whitney $U$ test were used to compare subgroups, and analysis of variance or the Kruskal-Wallis tests were used to compare differences among the three CCS subgroups. Categorical variables are reported as the number (proportion, \%) and were compared using Pearson's chi-squared test. Potential correlations between qPCR data and immunohistochemical quantification or clinical parameters (serum CRP, VAT area, and EAT volume) were assessed using Pearson's correlation coefficient. Linear regression was used to examine the clinical factors related to qPCR data of EAT samples for multivariate analysis adjusted for age, sex, coronary risk factors, stain therapy, $\mathrm{CABG}$ versus. non-CABG, VAT area, and EAT volume. All analyses were undertaken using JMP 10.0.1 statistical software (SAS Institute, Cary, NC, USA). $P$ values $<0.05$ were considered statistically significant. 

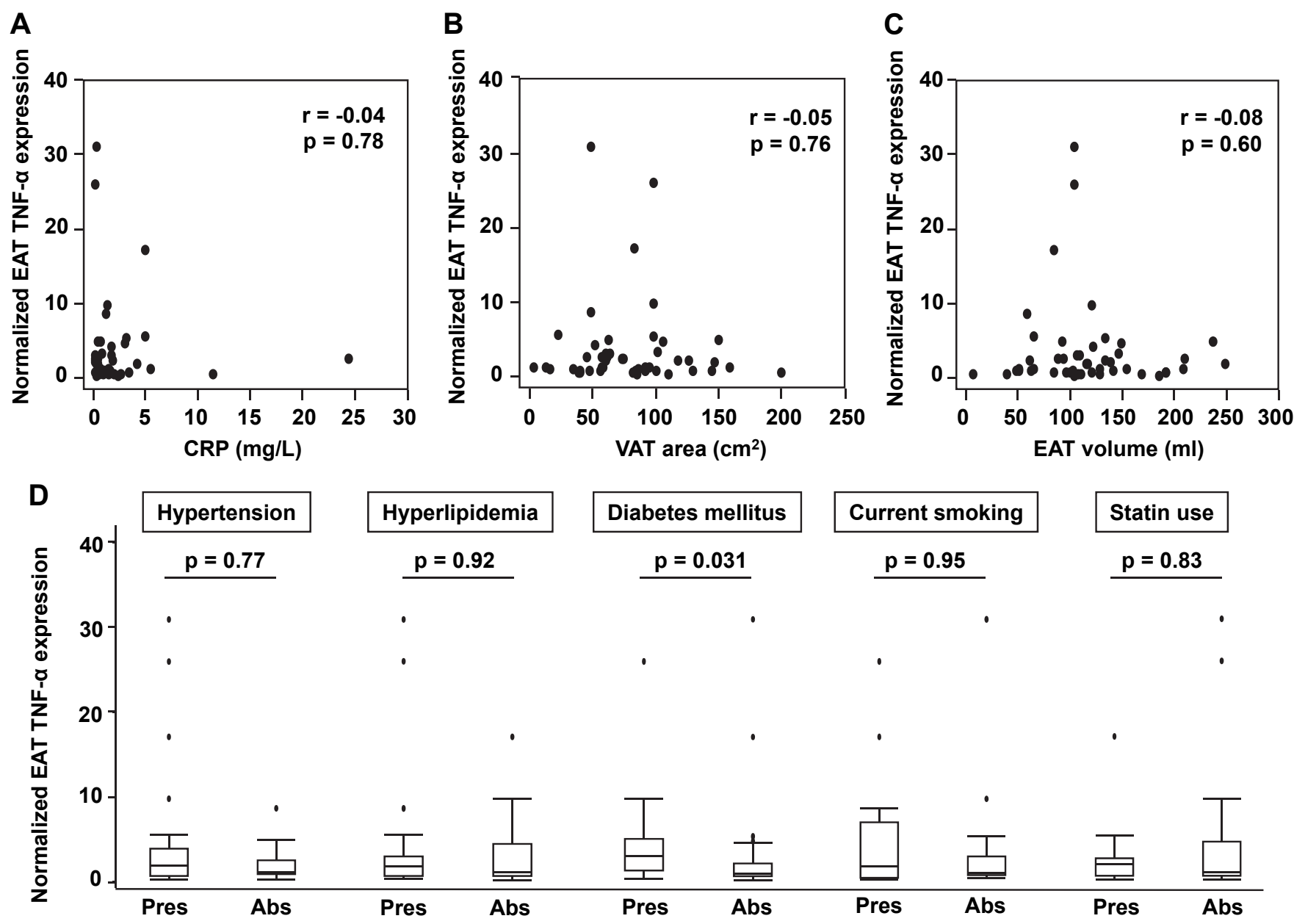

Fig. 2. Normalized tumor necrosis factor (TNF)- $\alpha$ expression in epicardial adipose tissue (EAT) had no correlation with serum C-reactive protein (CRP) or visceral adipose tissue (VAT) area or EAT volume (A-C). Normalized TNF- $\alpha$ expression in EAT was significantly higher in patients with diabetes mellitus, and it had no difference based on the presence of other risk factors or statin therapy (D). Pres, present; Abs, absent.

\section{Results}

\section{Baseline Characteristics}

Pre-surgery CT examinations identified 11 patients with mild CCS, 15 with moderate CCS, and 21 with severe CCS group. Twenty-three (48.9\%) patients had at least one NCP, and 21 (44.7\%) had obstructive coronary stenosis on CCTA; all 21 with obstructive coronary stenosis were scheduled for elective CABG. The demographic and clinical characteristics of the cohort and subgroups are shown in Table 1. Patients scheduled for CABG and those with severe CCS or NCP on CCTA had significantly more coronary risk factors and were more likely to be taking a statin. Serum triglyceride level was higher in patients with NCP, whereas the other lipid levels were similar between the subgroups. Hemoglobin A1c was higher in patients scheduled for CABG and those with severe CCS or NCP.
The subgroups showed no significant differences in serum CRP concentration and EAT volume.

In the entire cohort, the TNF- $\alpha$ expression level of EAT normalized to that of paired SAT sample was $1.19[0.72-3.16]$, which was significantly higher than $1(p<0.001)$. The macrophage count in EAT was 48 [36-71]. The normalized TNF- $\alpha$ expression tended to correlate positively with the macrophage infiltration in EAT, but their correlation did not reach significant $(r=0.28, p=0.059)$ (Fig. 1).

\section{TNF- $\alpha$ Expression in EAT and Clinical Character- istics}

We examined whether there was a relationship between normalized TNF- $\alpha$ expression and systemic inflammatory biomarker or adipose tissue quantity. The TNF- $\alpha$ expression level did not correlate with serum CRP concentration $(r=-0.04, p=0.78$, Fig. $2 A)$. There 

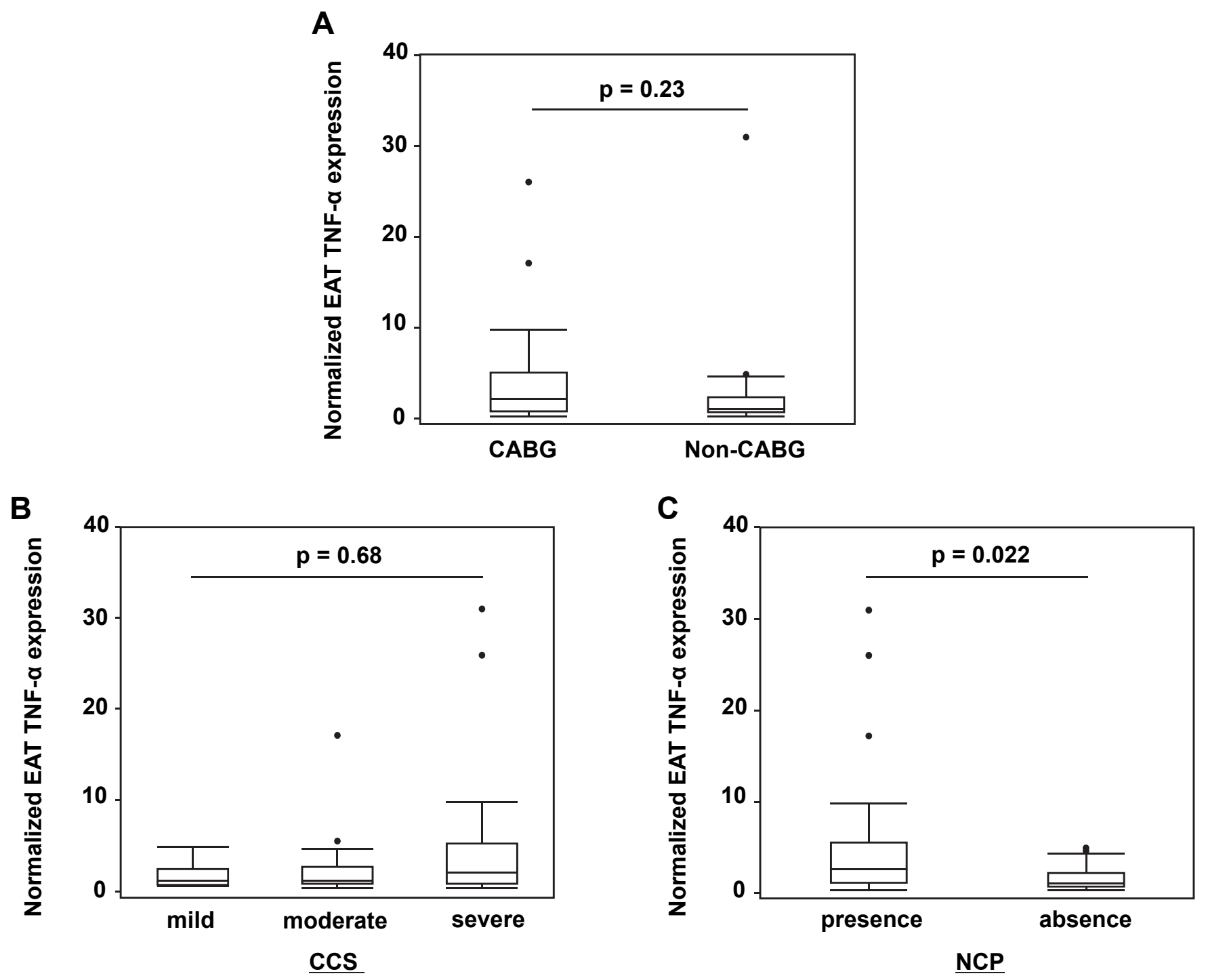

Fig. 3. Normalized tumor necrosis factor (TNF)- $\alpha$ expression in epicardial adipose tissue (EAT) had no difference between patients scheduled for coronary artery bypass graft surgery (CABG) and those scheduled for non-CABG (A). There was no significant difference in normalized TNF- $\alpha$ expression in EAT among the three groups based on coronary calcium score (CCS) (B). Patients with non- and/or partially-calcified coronary plaque (NCP) had higher normalized TNF- $\alpha$ expression in EAT than those without $(\mathrm{C})$.

was no correlation between VAT area and TNF- $\alpha$ expression level $(r=-0.05, p=0.76$, Fig. 2B), and between EAT volume and TNF- $\alpha$ expression level $(r=-0.08$, $p=0.60$, Fig. 2C).

As for the influence of coronary risk factors, patients with diabetes mellitus had significantly higher TNF- $\alpha$ expression level than those without (3.03 [1.145.23] versus 1.07 [0.68-2.32], $p=0.031$ ), but the presence of other risk factors had no impact on TNF- $\alpha$ expression level (Fig. 2D). Statin therapy did not appear to influence TNF- $\alpha$ expression level (Fig. 2D): it was $1.99(0.71-2.83)$ in those taking statins compared with $1.16(0.75-4.70)$ in those who were not $(p=0.83)$.

\section{TNF- $\alpha$ Expression in EAT and Clinical Presentation of Coronary Atherosclerosis}

Fig. 3 shows normalized TNF- $\alpha$ expression based on $\mathrm{CABG}$ or non-CABG background or CT-based coronary atherosclerosis. Patients scheduled for CABG, who all had obstructive coronary stenosis on CCTA, showed no difference in TNF- $\alpha$ expression level with those scheduled for non-CABG surgery (2.14 [0.725.05] versus. 1.09 [0.70-2.36], $p=0.23$, Fig. 3A). Among the three CCS groups, there was no difference in TNF- $\alpha$ expression level $(p=0.68$, Fig. 3B), while patients with NCP had significantly higher TNF- $\alpha$ expression level than those without $(2.50[1.01-5.53]$ ver- 
sus. 1.03 [0.64-2.17], $p=0.022$, Fig. 3C). On multivariate analysis adjusted for age, sex, coronary risk factors, statin use, CABG versus non-CABG, VAT area, and EAT volume, the presence of NCP was significantly correlated with increased TNF- $\alpha$ expression level $(\beta=0.79, p=0.003$, Table 2).

Typical immunohistochemical and qPCR findings from representative cases are shown in Fig. 4.

\section{Discussion}

In the present study, we reported the relationship between EAT TNF- $\alpha$ gene expression verified by qPCR and coronary atherosclerosis assessed on clinical cardiac CT images. The evidence of the association between inflammatory cytokine expression in EAT and clinically-assessed coronary atherosclerosis is limited. We used TNF- $\alpha$ mRNA expression in EAT normalized to that in SAT to examine its EAT-specific expression, and: (1) validated the regionally enhanced expression of TNF- $\alpha$ mRNA in EAT; (2) found no relationship between normalized EAT TNF- $\alpha$ expression and a marker of systemic inflammation (serum CRP concentration) or clinical adipose tissue quantity (VAT area and EAT volume); (3) found that requirement for CABG (corresponding to presence of obstructive coronary stenosis in this study) and severity of coronary calcification did not appear to correlate with normalized EAT TNF- $\alpha$ expression; and (4) found that elevated normalized EAT TNF- $\alpha$ expression independently correlated with NCP formation seen on CT, suggestive of the progressive stage of coronary atherosclerosis. Our findings support the theory that EAT is a source of direct mediators of the pathogenesis of coronary atherosclerosis. Especially, they may underline that regional TNF- $\alpha$ expression in EAT exerts potent effects on the progression of coronary atherosclerosis that is not modulated by statin therapy.

\section{Condition of TNF- $\alpha$ in EAT}

Adipocytes in VAT have been shown to secrete biologically active substances that provoke the metabolic syndrome ${ }^{26)}$, and are thought to be more endocrinologically active than those in SAT ${ }^{27)}$. In this study, we demonstrate that EAT, which shares a common embryologic origin with VAT, is associated with enhanced expression of a major inflammatory cytokine, TNF- $\alpha$, compared with SAT. This concurs with a previous report showing higher TNF- $\alpha$ expression by EAT than SAT in patients with critical CAD ${ }^{28)}$, and highlights the status of EAT as 'diseased' adipose tissue in diverse cardiovascular patient populations.

Suganami et al. demonstrate that free fatty acids and TNF- $\alpha$ contribute to a cycle that augments the
Table 2. Linear regression analysis to examine the clinical factors related to the normalized TNF- $\alpha$ expression in EAT.

\begin{tabular}{|c|c|c|c|c|}
\hline \multirow{2}{*}{ Variables } & \multicolumn{2}{|c|}{ Univariate } & \multicolumn{2}{|c|}{ Multivariate } \\
\hline & $\beta$ & $p$ value & $\beta$ & $p$ value \\
\hline Age (years) & 0.02 & 0.87 & & \\
\hline Male sex & 0.31 & 0.031 & 0.28 & 0.088 \\
\hline Hypertension & 0.16 & 0.29 & & \\
\hline Hyperlipidemia & 0.07 & 0.62 & & \\
\hline Diabetes mellitus & 0.13 & 0.38 & & \\
\hline Current smoking & 0.16 & 0.28 & & \\
\hline Statin use & -0.15 & 0.33 & & \\
\hline Candidate for CABG & 0.09 & 0.57 & & \\
\hline VAT area $\left(\mathrm{cm}^{2}\right)$ & -0.05 & 0.76 & & \\
\hline EAT volume (ml) & -0.08 & 0.60 & & \\
\hline NCP presence & 0.34 & 0.019 & 0.79 & 0.003 \\
\hline
\end{tabular}

CABG, coronary artery bypass graft surgery; EAT, epicardial adipose tissue; NCP, non-calcified coronary plaque; TNF- $\alpha$, tumor necrosis factor- $\alpha$; VAT, visceral adipose tissue.

inflammatory changes in both adipocytes and macrophages ${ }^{15)}$. Imoto-Tsubakimoto et al. highlight serglycin, which is one of the most abundantly expressed protein in EAT and induced by TNF- $\alpha$, and suggest that serglycin and TNF- $\alpha$ likely contribute to development of CAD through cross-talk between adipocytes and macrophages ${ }^{29}$. Although TNF- $\alpha$ is known as a major monocyte-derived cytokine, TNF- $\alpha$ expression level in EAT does not appear to be determined only by macrophage infiltration based on our result. It indicates that there are several inherent confounding factors, such as fatty acids and serglycin, that influence TNF- $\alpha$ profile in EAT.

\section{Correlation of EAT TNF- $\alpha$ with Clinical Parameters}

We found no correlation between normalized EAT TNF- $\alpha$ expression and serum CRP concentration. Despite a lack of high-sensitivity CRP measurements, this result indicates that EAT predominantly exerts local and paracrine, rather than systemic, effects. We previously reported that EAT macrophage infiltration quantified by immunohistochemical staining had no correlation with clinically-quantified adipose tissue $^{12)}$. Normalized TNF- $\alpha$ expression similarly had no correlation with the adipose tissue quantification in this study. It suggests that regional TNF- $\alpha$ expression in EAT is independent of EAT volume, or does not change in parallel to EAT volume. The presence of diabetes mellitus was associated with higher EAT TNF- $\alpha$ expression, which may reflect the hypothesis that adipose-derived TNF- $\alpha$ function correlates with the development of insulin resistance ${ }^{30)}$. However, the linear 
A
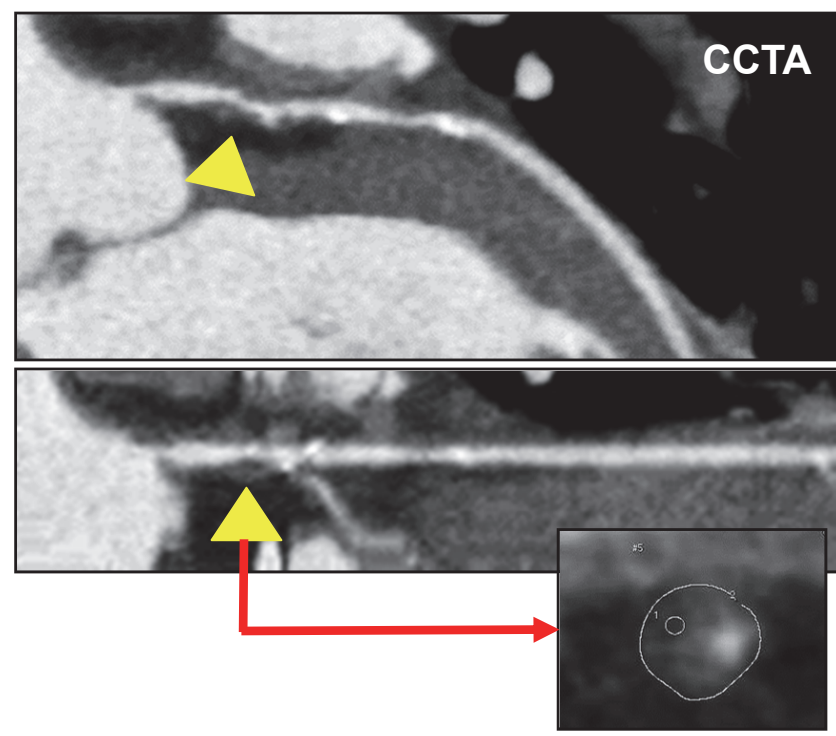

B
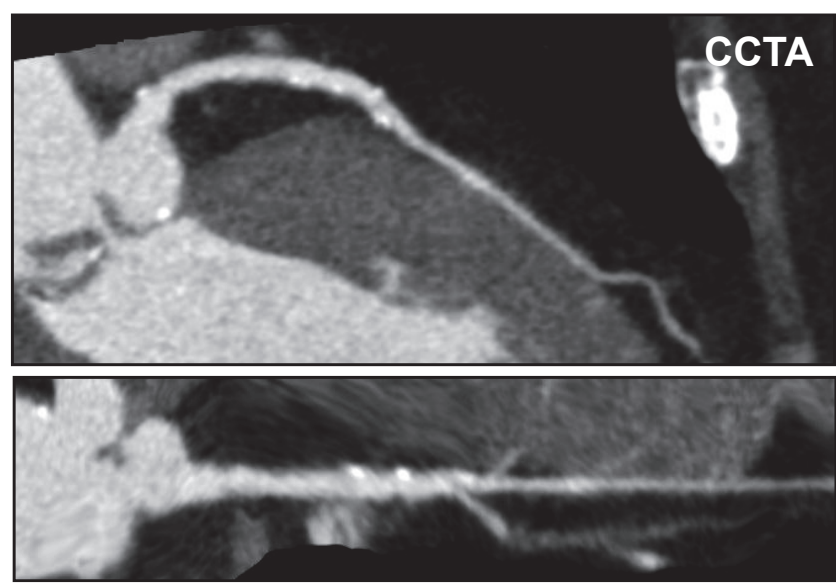

EAT immunohistochemistry, CD68 (x200)

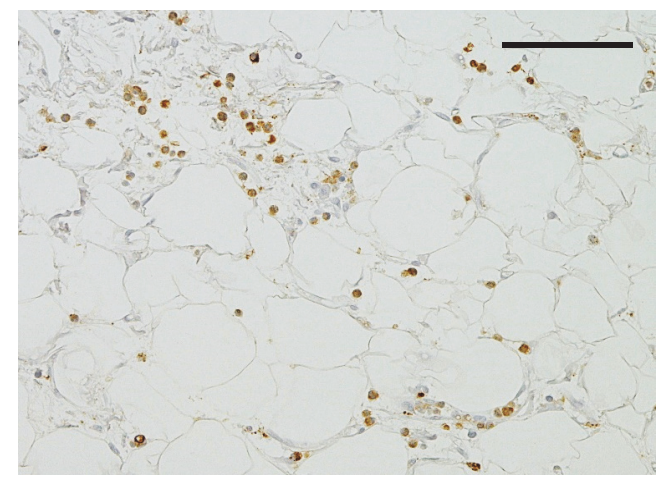

The normalized TNF- $\alpha$ expression : 17.11

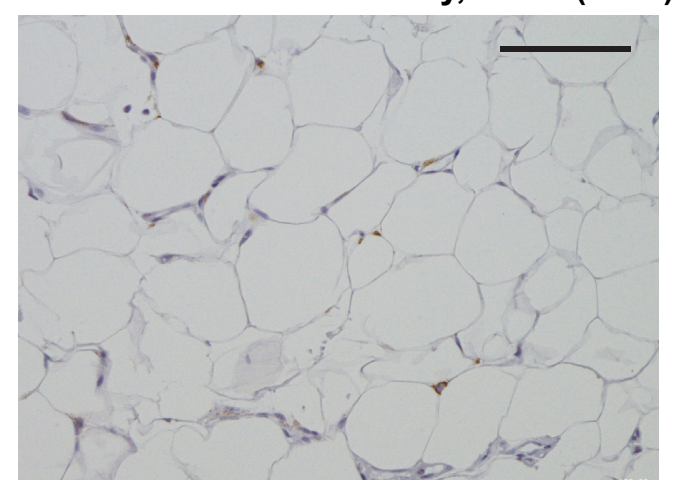

The normalized TNF- $\alpha$ expression : 0.58

Fig.4. Illustrative cases. (A) A 67-year-old male patient scheduled for coronary artery bypass graft surgery (CABG) taking 10 mg daily dose of atorvastatin with non-calcified coronary plaque (arrowheads) on coronary computed tomography angiography (CCTA), extensive histological macrophage infiltration in epicardial adipose tissue (EAT), and high normalized tumor necrosis factor (TNF)- $\alpha$ expression in EAT. (B) A 72-year-old female scheduled for aortic valve repair taking no statin with only mild coronary calcification on CCTA, minimal histological macrophage infiltration in EAT, and low normalized TNF- $\alpha$ expression in EAT. Scale bar in immunohistochemistry image, $100 \mu \mathrm{m}$.

regression analysis showed no correlation between diabetes mellitus and elevation of EAT TNF- $\alpha$ expression. Thus, we cannot confirm the hypothesis in this study. The anti-inflammatory effects of statin are well known, but we found no effect of statin therapy on normalized EAT TNF- $\alpha$ expression.

\section{Significance of EAT TNF- $\alpha$ to CAD and Coronary Atherosclerosis \\ Hirata et al. have reported that pro-inflammatory cytokines in EAT are associated with the presence and severity of CAD (the latter assessed by angiography}

using Gensini score) ${ }^{31}$. However, the difference in normalized EAT TNF- $\alpha$ expression between patients with obstructive coronary stenosis (those scheduled for $C A B G$ ) and those without did not reach significance in the current study. Notably, while normalized EAT TNF- $\alpha$ expression had no correlation with severity of coronary calcification, its increase correlated with NCP formation independently of statin use, CABG or non-CABG status, and extent of adipose tissue. The presence of NCP, including heterogeneous (partially calcified) plaques, on CCTA is thought to represent a stage in the process of coronary atherosclerosis 
growing, rather than an advanced stage characterized by heavy coronary calcification. Our data raise the possibility that increased TNF- $\alpha$ expression in EAT, independent of EAT volume, contributes to subclinical progression of coronary atherosclerosis.

Data from a registry of patients with rheumatoid arthritis show that those responding to anti-TNF- $\alpha$ therapy have lower risk of future myocardial infarction than non-responders ${ }^{32}$. A report from observational cohorts also suggests that TNF- $\alpha$ blockade reduces the risk of all cardiovascular events - including myocardial infarction - in rheumatoid arthritis patients ${ }^{33)}$. The effect of anti-TNF- $\alpha$ therapy on EAT biology and $\mathrm{CAD}$ progression may be worthy of investigation in broader patient populations.

\section{Limitations}

First, its small sample size might result in a patient selection bias and potential failures to reach statistical significance when examining differences in TNF- $\alpha$ levels between subgroups. As shown in Supplementary Fig. 1, the majority of the patients with NCP on CCTA were scheduled for CABG, and there is a limitation in assessing the difference in the impact of EAT inflammation on coronary atherosclerosis between CABG and non-CABG patients. Additionally, we did not find possible associations between normalized EAT TNF- $\alpha$ expression and specific non-CAD, such as aortic valve disease ${ }^{34)}$, in this study (Supplementary Fig. 2A), which should be further investigated in more subjects. Second, we focused on one representative cytokine that was expected to play a major biologic role in EAT based on previous reports, and only evaluated its expression at gene level; investigations of the expression of other cytokines and at protein level should further elucidate the pathophysiologic mechanisms active in EAT, which are our next issues. Nevertheless, our findings here highlight the pathologic significance of the specific cytokine in EAT, and provide introductory information enhancing further investigation of EAT molecular action on CAD. Third, when we evaluated CT-based high-risk features of NCP (minimum CT density $<30 \mathrm{HU}$ and vascular remodeling index $>1.1)^{20,21)}$, we found no association between normalized EAT TNF- $\alpha$ expression and the presence or absence of those (Supplementary Fig. 2B), which might be a consequence of the small number of subjects with NCP on CCTA. We recommend further study of the influence of EAT cytokine expression on coronary plaque characteristics assessed by a variety of clinical imaging modalities, such as CCTA, intravascular ultrasound, and optical coherence tomography, in larger cohorts. Fourth, to investigate the systemic effects of TNF- $\alpha$ expression in EAT, it may be required to measure TNF- $\alpha$ level in the peripheral blood and analyze its correlation with EAT TNF- $\alpha$ expression and the other clinical parameters (CRP concentration or adipose tissue quantification).

\section{Conclusions}

We identified elevated expression of a gene encoding the specific inflammatory cytokine, TNF- $\alpha$, in EAT. Having normalized mRNA level in EAT to that in SAT, elevated TNF- $\alpha$ expression was independently correlated with NCP formation seen on CCTA, suggestive of the progressive stage of coronary atherosclerosis. Our results suggest that EAT contributes to CAD through molecule behavior and that TNF- $\alpha$ is the key atherogenic cytokine in EAT.

\section{Disclosures}

None of the authors have any conflicts of interest to disclose.

\section{Acknowledgements and Notice of Grant Support}

We would like to thank Ai Nimura for help in conducting qPCR.

This study was supported by a Japan Heart Foundation Research Grant, by a Takeda Science Foundation Research Grant, and by JSPS KAKENHI Grant Numbers JP26870395, JP23591044.

\section{References}

1) Sacks HS, Fain JN. Human epicardial adipose tissue: a review. Am Heart J, 227; 153: 907-917

2) Nakanishi R, Rajani R, Cheng VY, Gransar H, Nakazato R, Shmilovich H, Otaki Y, Hayes SW, Thomson LE, Friedman JD, Slomka PJ, Berman DS, Dey D. Increase in epicardial fat volume is associated with greater coronary artery calcification progression in subjects at intermediate risk by coronary calcium score: a serial study using noncontrast cardiac CT. Atherosclerosis, 2011; 218: 363-368

3) Yerramasu A, Dey D, Venuraju S, Anand DV, Atwal S, Corder R, Berman DS, Lahiri A . Increased volume of epicardial fat is an independent risk factor for accelerated progression of sub-clinical coronary atherosclerosis. Atherosclerosis, 2012; 220: 2223-2230

4) Oka T, Yamamoto H, Ohashi N, Kitagawa T, Kunita E, Utsunomiya H, Yamazato R, Urabe Y, Horiguchi J, Awai K, Kihara Y. Association between epicardial adipose tissue volume and characteristics of non-calcified plaques assessed by coronary computed tomographic angiography. Int J Cardiol, 2012; 161: 45-49

5) Alexopoulos N, McLean DS, Janik M, Arepalli CD, Still- 
man AE, Raggi P. Epicardial adipose tissue and coronary plaque characteristics. Atherosclerosis, 2010; 210: 150154

6) Rajani R, Shmilovich H, Nakazato R, Nakanishi R, Otaki Y, Cheng VY, Hayes SW, Thomson LE, Friedman JD, Slomka PJ, Min JK, Berman DS, Dey D. Relationship of epicardial fat volume to coronary plaque, severe coronary stenosis, and high-risk coronary plaque features assessed by coronary CT angiography. J Cardiovasc Comput Tomogr, 2013; 7: 125-132

7) Hwang IC, Park HE, Choi SY. Epicardial adipose tissue contributes to the development of non-calcified coronary plaque: A 5-year computed tomography follow-up study. J Atherocler Thromb, 2017; 24: 262-274

8) Tanami Y, Jinzaki M, Kishi S, Matheson M, Vavere AL, Rochitte CE, Dewey M, Chen MY, Clouse ME, Cox C, Kuribayashi S, Lima JA, Arbab-Zadeh A. Lack of association between epicardial fat volume and extent of coronary artery calcification, severity of coronary artery disease, or presence of myocardial perfusion abnormalities in a diverse, symptomatic patient population: results from the CORE320 multicenter study. Circ Cardiovasc Imaging, 2015; 8: e002676

9) Kremen J, Dolinkova M, Krajickova J, Blaha J, Anderlova K, Lacinova Z, Haluzikova D, Bosanska L, Vokurka M, Svacina S, Haluzik M. Increased subcutaneous and epicardial adipose tissue production of proinflammatory cytokines in cardiac surgery patients: possible role in postoperative insulin resistance. J Clin Endocrinol Metab, 2006; 91: 4620-4627

10) Iacobellis G, Bianco AC. Epicardial adipose tissue: emerging physiological, pathophysiological and clinical features. Trends Endocrinol Metab, 2011; 22: 450-457

11) Alexopoulos N, Katritsis D, Raggi P. Visceral adipose tissue as a source of inflammation and promoter of atherosclerosis. Atherosclerosis, 2014; 233: 104-112

12) Kitagawa $T$, Yamamoto $H$, Sentani $K$, Takahashi $S$, Tsushima H, Senoo A, Yasui W, Sueda T, Kihara Y. The relationship between inflammation and neoangiogenesis of epicardial adipose tissue and coronary atherosclerosis based on computed tomography analysis. Atherosclerosis, 2015; 243: 293-299

13) Kleemann R, Zadelaar S, Kooistra T. Cytokines and atherosclerosis: a comprehensive review of studies in mice. Cardiovasc Res, 2008; 79: 360-376

14) Maury E, Noël L, Detry R, Brichard SM. In vitro hyperresponsiveness to tumor necrosis factor-alpha contributes to adipokine dysregulation in omental adipocytes of obese subjects. J Clin Endocrinol Metab, 2009; 94: 1393-1400

15) Suganami T, Nishida J, Ogawa Y. A paracrine loop between adipocytes and macrophages aggravates inflammatory changes: role of free fatty acids and tumor necrosis factor alpha. Arterioscler Thromb Vasc Biol, 2005; 25: 2062-2068

16) Kitagawa T, Yamamoto H, Urabe Y, Tsushima H, Utsunomiya H, Tatsugami F, Awai K, Kihara Y. Age- and sexrelated differences in coronary plaque high-risk features in patients with acute coronary syndrome assessed by computed tomography angiography. Int J Cardiol, 2014; 174: 744-747

17) Ohashi N, Yamamoto H, Horiguchi J, Kitagawa T, Hirai
N, Ito K, Kohno N. Visceral fat accumulation as a predictor of coronary artery calcium as assessed by multislice computed tomography in Japanese patients. Atherosclerosis, 2009; 202: 192-199

18) Ohashi N, Yamamoto H, Horiguchi J, Kitagawa T, Kunita E, Utsunomiya H, Oka T, Kohno N, Kihara Y. Association between visceral adipose tissue area and coronary plaque morphology assessed by CT angiography. JACC Cardiovasc Imaging, 2010; 3; 908-917

19) Sarin S, Wenger C, Marwaha A, Qureshi A, Go BD, Woomert CA, Clark K, Nassef LA, Shirani J. Clinical significance of epicardial fat measured using cardiac multislice computed tomography. Am J Cardiol, 2008; 102: 767-771

20) Kitagawa T, Yamamoto H, Ohhashi N, Okimoto T, Horiguchi J, Hirai N, Ito K, Kohno N. Comprehensive evaluation of non-calcified coronary plaque characteristics detected using 64-slice computed tomography in patients with proven or suspected coronary artery disease. Am Heart J, 2007; 154: 1191-1198

21) Kitagawa T, Yamamoto $H$, Horiguchi J, Ohhashi N, Tadehara F, Shokawa T, Dohi Y, Kunita E, Utsunomiya H, Kohno N, Kihara Y. Characterization of noncalcified coronary plaques and identification of culprit lesions in patients with acute coronary syndrome by 64-slice computed tomography. JACC Cardiovasc Imaging, 2009; 2: 153-160

22) Urabe $Y$, Yamamoto H, Kitagawa T, Utsunomiya H, Tsushima H, Tatsugami F, Awai K, Kihara Y. Identifying small coronary calcification in non-contrast $0.5-\mathrm{mm}$ slice reconstruction to diagnose coronary artery disease in patients with a conventional zero coronary artery calcium score. J Atherocler Thromb, 2016; 23: 1324-1333

23) Budoff MJ, Shaw LJ, Liu ST, Weinstein SR, Mosler TP, Tseng PH, Flores FR, Callister TQ, Raggi P, Berman DS. Long-term prognosis associated with coronary calcification: observation from a registry of 25,253 patients. J Am Coll Cardiol, 2007; 49: 1860-1870

24) Detrano R, Guerci AD, Carr JJ, Bild DE, Burke G, Folsom AR, Liu K, Shea S, Szklo M, Bluemke DA, O'Leary DH, Tracy R, Watson K, Wong ND, Kronmal RA. Coronary calcium as a predictor of coronary events in four racial or ethnic groups. N Eng J Med, 2008; 358: 13361345

25) Yamamoto $H$, Ohashi N, Ishibashi K, Utsunomiya $H$, Kunita E, Oka T, Horiguchi J, Kihara Y. Coronary calcium score as a predictor for coronary artery disease and cardiac events in Japanese high-risk patients. Circ J, 2011; 75: 2424-2431

26) Matsuzawa Y, Funahashi T, Nakamura T. Molecular mechanism of metabolic syndrome $\mathrm{X}$ : contribution of adipocytokines adipocyte-derived bioactive substances. Ann N Y Acad Sci, 1999; 892: 146-154

27) Hajer GR, van Haeften TW, Visseren FL. Adipose tissue dysfunction in obesity, diabetes, and vascular diseases. Eur Heart J, 2008; 29: 2959-2971

28) Mazurek T, Zhang L, Zalewski A, Mannion JD, Diehl JT, Arafat H, Sarov-Blat L, O'Brien S, Keiper EA, Johnson AG, Martin J, Goldstein BJ, Shi Y. Human epicardial adipose tissue is a source of inflammatory mediators. Circulation, 2003; 108: 2460-2466 
29) Imoto-Tsubakimoto $H$, Takahashi $T$, Ueyama T, Ogata $T$, Adachi A, Nakanishi N, Mizushima K, Naito Y, Matsubara H. Serglycin is a novel adipocytokine highly expressed in epicardial adipose tissue. Biochem Biophys Res Commun, 2013; 432: 105-110

30) Hotamisligil GS, Arner P, Caro JF, Atkinson RL, Spiegelman BM. Increased adipose tissue expression of tumor necrosis factor-alpha in human obesity and insulin resistance. J Clin Invest, 1995; 95: 2409-2415

31) Hirata Y, Tabata M, Kurobe H, Motoki T, Akaike M, Nishio C, Higashida M, Mikasa H, Nakaya Y, Takanashi S, Igarashi T, Kitagawa T, Sata M. Coronary atherosclerosis is associated with macrophage polarization in epicardial adipose tissue. J Am Coll Cardiol, 2011; 58: 248-255

32) Dixon WG, Watson KD, Lunt M, Hyrich KL, Silman AJ,
Symmons DP. Reduction in the incidence of myocardial infarction in patients with rheumatoid arthritis who respond to anti-tumor necrosis factor alpha therapy: results from the British Society for Rheumatology Biologics Register. Arthritis Rheum, 2007; 56: 2905-2912

33) Barnabe C, Martin BJ, Ghali WA. Systematic review and meta-analysis: anti-tumor necrosis factor alpha therapy and cardiovascular events in rheumatoid arthritis. Arthritis Care Res, 2011; 63: 522-529

34) Parisi V, Rengo G, Pagano G, D'Esposito V, Passaretti F, Caruso A, Grimaldi MG, Lonobile T, Baldascino F, De Bellis A, Formisano P, Ferrara N, Leosco D. Epicardial adipose tissue has an increased thickness and is a source of inflammatory mediators in patients with calcific aortic stenosis. Int J Cardiol, 2015; 186: 167-169 
A

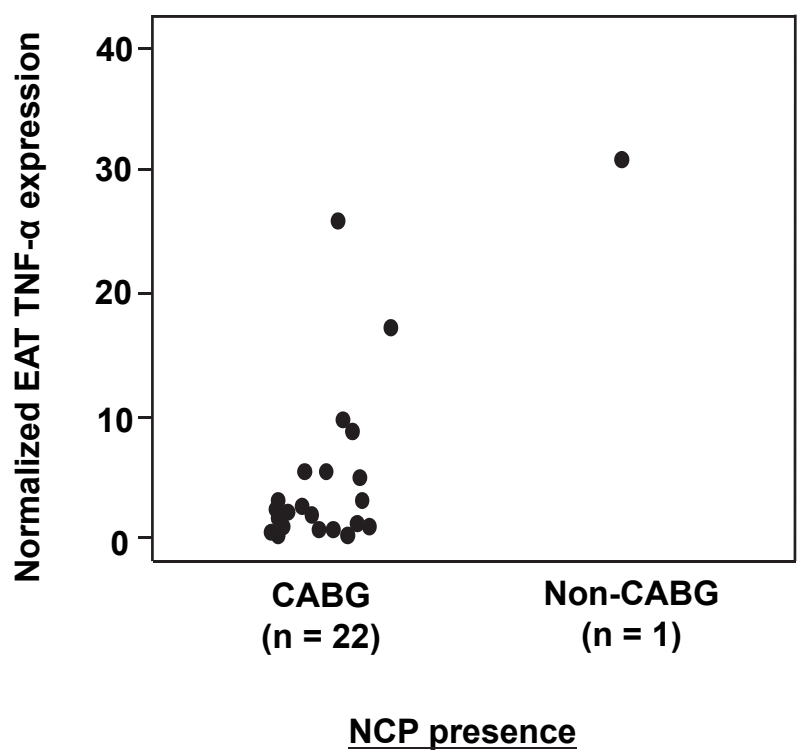

B

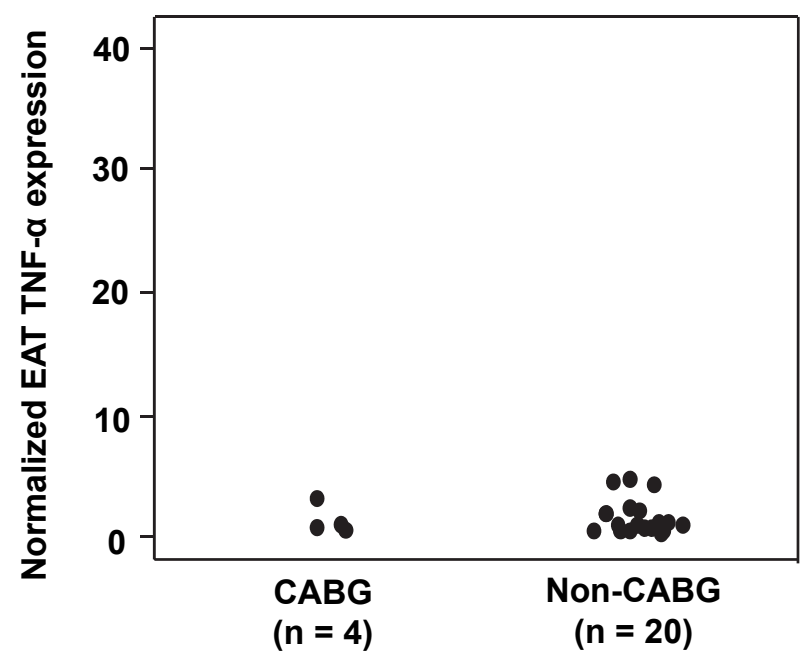

NCP absence

Supplementary Fig. 1. The data plots of normalized tumor necrosis factor (TNF)- $\alpha$ expression in epicardial adipose tissue (EAT) based on the presence (A) or absence (B) of non- and/or partially-calcified coronary plaque (NCP).

A

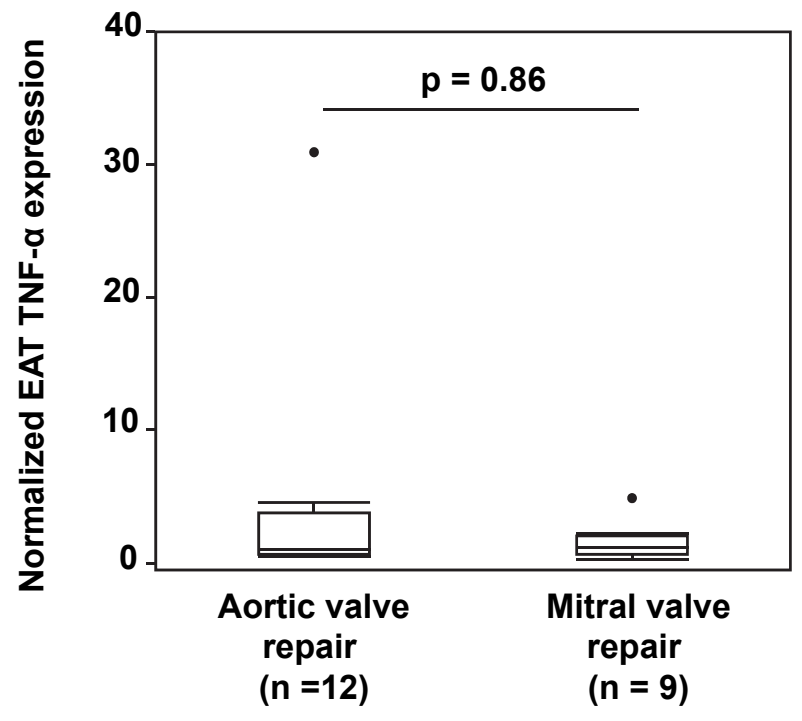

Scheduled surgery
B

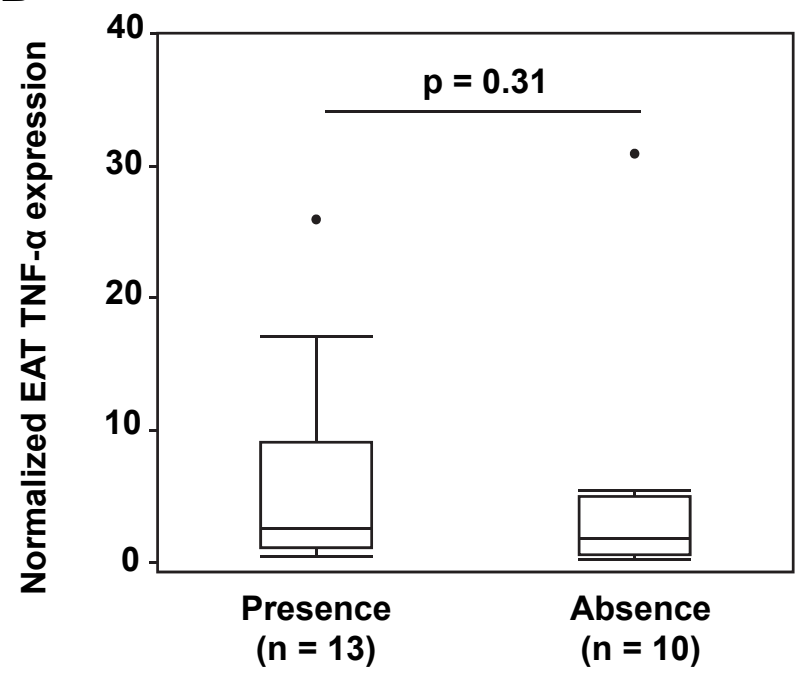

NCP with high-risk features

Supplementary Fig. 2. Normalized tumor necrosis factor (TNF)- $\alpha$ expression in epicardial adipose tissue (EAT) showed no significant difference between patients scheduled for aortic valve repair and those scheduled for mitral valve repair (A). High-risk features of non- and/or partially-calcified coronary plaque (NCP) on computed tomography (CT) were defined as minimum CT density $<30$ Hounsfield units and vascular remodeling index $>1.1$. Normalized TNF- $\alpha$ expression in EAT showed no significant difference between patients with highrisk NCP and those without (B). 